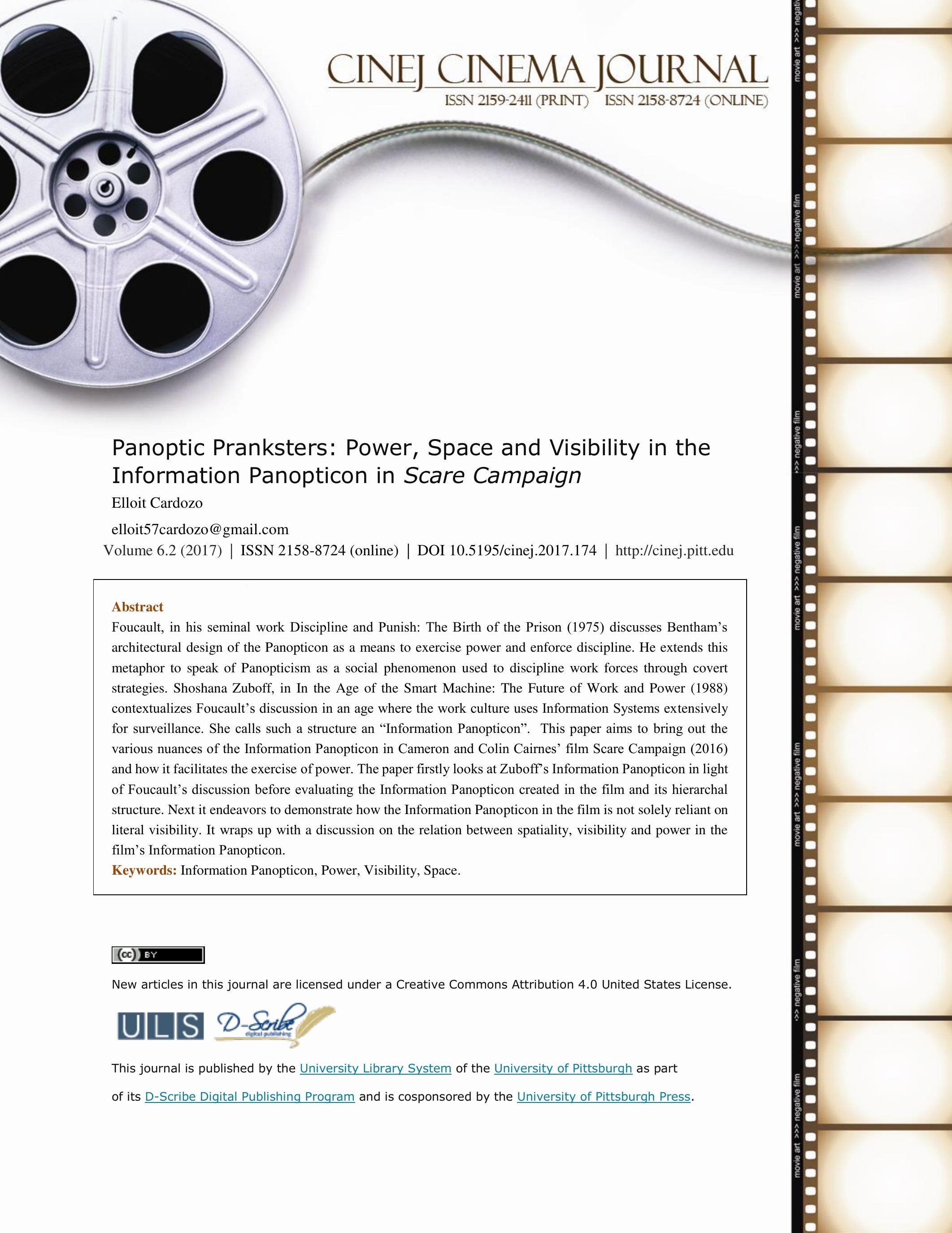




\section{Panoptic Pranksters: Power, Space and Visibility in the Information Panopticon in Scare Campaign}

\section{Elloit Cardozo}

\section{Introduction}

At first glance, Cameron and Colin Cairnes' Scare Campaign appears to be merely a story of a prank gone horribly wrong. However, the way that the pranksters use Information Systems in order to manipulate and prank their stooges in the film forms the subject for an extremely compelling study. Foucault in his seminal work Discipline and Punish: The Birth of the Prison (1975) discusses Bentham's architectural design of the Panopticon as a means to exercise power and enforce discipline. He extends this metaphor to speak of Panopticism as a social phenomenon used to discipline work forces through covert strategies. Shoshana Zuboff, in In the Age of the Smart Machine: The Future of Work and Power (1988) contextualizes Foucault's discussion in an age where the work culture uses Information Systems extensively for surveillance. She calls such a structure an "Information Panopticon". This paper aims to bring out the various nuances of the Information Panopticon in Cameron and Colin Cairnes' film Scare Campaign (2016) and how it facilitates the exercise of power. The paper firstly looks at Zuboff's Information Panopticon in light of Foucault's discussion before evaluating the Information Panopticon created in the film and its hierarchal structure. Next it endeavors to demonstrate how the Information Panopticon in the film is not solely reliant on literal visibility. It wraps up with a discussion on the relation between spatiality, visibility and power in the film's Information Panopticon. 


\section{The Panopticon and the Information Panopticon}

Michel Foucault, in Discipline and Punish: The Birth of the Prison discusses at length Jeremy Bentham's architectural structure of the Panopticon. Bentham's Panopticon is a structure which was used for the continuous supervision of captives. It had:

at the periphery, an annular building; at the centre, a tower; this tower is pierced with wide windows that open onto the inner side of the ring; the peripheric building is divided into cells, each of which extends the whole width of the building; they have two windows, one on the inside, corresponding to the windows of the tower; the other, on the outside, allows the light to cross the cell from one end to the other. (Foucault 1995, 200)

Bentham's architectural figure, by reducing a captive to absolute visibility, according to Foucault becomes a medium to exercise power and to discipline. Using Bentham's Panopticon as a cornerstone, Foucault coins the term "Panopticism" (1995, 208). He goes on to discuss Panopticism as a social phenomenon where various forms of rigorous surveillance are used to discipline work forces and school children among other social groups. Shoshana Zuboff, in her book In the Age of the Smart Machine: The Future of Work and Power, applies Foucault's ideas of Panopticism to modern work culture and points out how Information Systems or Information and Communications Technology (ICT) can be used in a similar way to Bentham's architectural structure:

Information systems that translate, record, and display human behavior can provide the computer age version of universal transparency with a degree of illumination that would have exceeded even Bentham's most outlandish fantasies. Such systems can become information panopticons that, freed from the constraints of space and time, do not depend upon the physical arrangement of buildings or the laborious record keeping of industrial administration. They do not require the mutual presence of objects of observation [emphasis added] (Zuboff 1988, 322). 
An Information Panopticon, simply put, can be understood as a Panopticon created by the means of Information and Communications Technology or as Zuboff says, a "computer age version" (1988, 322) of Bentham's Panopticon. What Zuboff does in her discussion on the Information Panopticon is that she points out how technological advancements have made it possible to exercise power even more effortlessly, efficiently and selectively than ever before. It would hence be fair to say that the Information Panopticon is like the modern-day upgrade of Bentham's Panopticon.

Since an Information Panopticon does not require the mutual presence of the observer and the observed, it follows that in an Information Panopticon, one might not necessarily know that (s)he is being observed. This leads to a crucial departure from the Panopticon. In a Panopticon, it is "a state of conscious and permanent visibility that assures the automatic functioning of power" (Foucault 1995, 201). The consciousness or awareness of the possibility that one is being watched plays a crucial role in the disciplining of the observed in a Panopticon. With the possible removal of this consciousness, the Information Panopticon subsequently removes (or so it appears) the possibility to discipline. As Jake Goldenfein points out:

The relevance of the panopticon as a metaphor begins to wither when we start thinking about whether contemporary types of visuality (effectively digital and data-driven) are analogous to the central tower concept. (qtd. in McMullan, 2015)

Thomas McMullan, while discussing Internet Surveillance by various government bodies, points out how the nature of observation in certain Information Panopticons, where the person being observed is not aware, is different from the observation from a central tower in Bentham's Panopticon. This leads to a noticeable difference between Bentham's Panopticon and such an Information Panopticon. A possible explanation for this difference is the one that Goldenfein gives in stating that the subjects being observed totally unaware of it are being "normalized" (qtd. in 
McMullan, 2015). Another possible justification could be that "as crucial as visibility is to maintain power is also unverifiability" [emphasis in the original] (Koskela 2003, 298). However, on revisiting Foucault's discussion, one realizes that the role of a Panopticon is not merely to facilitate the disciplining of social groups. In discussing the Panopticon, Foucault clearly states that "[v]isibility is a trap" $(1995,200)$. It hence follows that visibility leads to subjugation while invisibility gives one access to power in a Panopticon. This is what Foucault calls "furtive power" $(1995,203)$.

Hence, an Information Panopticon in which the subject is unaware of the fact that (s)he is being observed is, apparently, a structure where absolute invisibility is not a means to maintaining but to exercising power. The paper will now proceed to evaluate this argument in light of the Information Panopticon in Scare Campaign.

\section{Marcus' Information Panopticon}

Given the complex nature of the plot of the film, it is helpful to firstly take a look at a brief synopsis. The plot of the film revolves around a prank planned by the crew of Scare Campaign (which is also the name of a TV prank show in the film). On being told that their show has "lost its edge" (Ezez. 2016), Marcus, the director, decides to push the limits with their next prank by pranking Rowan who is a former employee at a dungeon, in the very same dungeon where he planted people. The prank goes horribly wrong and Rowan starts killing the members of the Scare Campaign crew brutally, one by one. The first twist in the plot comes when it is revealed that it is in fact one of the actors of the Scare Campaign crew, Emma, who is the stooge for the prank and that Rowan (whose real name is Trent) is just a paid actor. Trent's killing spree is a part of the prank that Marcus plays on Emma. The second twist comes when it is made clear that the whole 
Scare Campaign crew is actually being pranked by the Masked Freaks, a group that uploads videos on the deep internet of extremely brutal pranks which finally end with all the stooges being killed. The third and final comes when it is revealed that Abby, the newest member of the Scare Campaign crew, is actually an accomplice of the Masked Freaks.

Given the nature of the twists in the plot of Scare Campaign's plot, it makes sense to break down the Information Panopticon in the film and look at it, one level at a time. Marcus, in his attempt to prank Emma, gets his crew to rig the prank location, a building which used to be a dungeon, with cameras. In doing this, Marcus makes (or so he believes) practically every nook and corner of the building visually accessible from the system in the control room. The fact that nearly the whole location is under video surveillance, enables Marcus to monitor both Emma and Trent's movements to a great extent. However, despite the access to power Marcus has, he is never totally in control of the situations around him. This is hinted at in the exchange just before the prank begins:

Emma: If something goes wrong today I promise I'll call time, alright?

Abby: Okay, it's fine. Marcus said, you know, the best pranks are the ones that go a little off script.

Emma: He only says that because nothing ever goes to script. (Ezez. 2016)

What, however, gives Marcus the ability to exercise power over his stooge, Emma, is the fact that he has access to information that Emma does not: while Emma does visit the control room several times, she does not know that Trent is actually a paid actor. This power dynamic is explicitly brought out in the scene where Emma reprimands Marcus for not having told her everything about Rowan who, she is made to believe, is the stooge:

Emma: He used to work here?

Marcus: That's the new paradigm Em, if I told you everything do you really think you'd be in the middle of what promises to be a fucking masterpiece? (Ezez. 2016) 
This exchange makes it clear that Marcus' access to power does not come only through his access to information but also through his ability to deprive others of it. In this way, by limiting Emma's access to information, Marcus successfully exercises his power over her up to a certain point in the film. The audience gradually finds out that Marcus, despite having so much access to power, is not aware of every tiny detail. This becomes somewhat evident when the Scare Campaign crew is preparing for the prank:

Marcus (looking into a hidden camera he notices): Hey, who's this little fellow? I don't remember that one being on the plan Tony.

Tony: Yeah, just thought I'd rig a few extra for you, boss. I know you love your options. Marcus: Good, man! (Ezez. 2016)

Thanks to this episode, Marcus takes every other camera which he notices included in the rigging of the location discreetly, despite not being on the plan, as having been put there by Tony. This proves to be a fatal mistake as it is gradually revealed. The audience is eventually given a hint that Marcus is not the only one who has set up an Information Panopticon in the film. When Emma is trying to escape from Trent because she believes he is trying to kill her, she asks Marcus for directions:

Emma: Which way do I go?

Marcus: Alright. No, no, no. No, we don't have any vision down there.

Emma: I'm looking right into a camera.

Marcus: You are? We got nothing up here. (Ezez. 2016)

\section{The Masked Freaks' Information Panopticon and its hierarchy}

The audience finds out towards the end of the film that the camera that Emma was looking into, in the aforementioned scene, was one of the several that the Masked Freaks set up. The Masked Freaks, in Scare Campaign, are "a well drilled, well-resourced global network of like- 
minded sickos" (Ezez. 2016) who upload videos on the deep internet of what "was just cool pranks: harassing and humiliating the homeless, that sort of thing. Then they graduated to torture, murder..." (Ezez. 2016). Marcus, who all the way believes that he is the one playing the prank turns out to be, along with the whole crew of his show, the stooge for the Masked Freaks' next prank. This twist in the plot totally exposes Marcus' lack of control over the situation despite having access to power, as hinted at in the earlier exchange between Emma and Abby. Exactly how well-drilled the Masked Freaks are is seen through the scrupulous planning and preparation that they put into the prank which is evident in how they set up an extremely thorough Information Panopticon. They not only rig the whole prank location with cameras of their own, but as Marcus and the audience find out towards the end, also hijack the Scare Campaign's whole data feed. This way, they automatically have access to the movements of all the stooges through cameras and even know all the stooges' next moves beforehand through the hijacked data feed which gives them the Scare Campaign crew's whole plan. The Information Panopticon that the Masked Freaks set up thrives on the fact that their stooges know nothing about what is happening: Marcus and his team (with the exception of Emma) are under the constant illusion that they have everything under control. The power that the Masked Freaks have access to through their Information Panopticon is effective because "it never intervenes, it is exercised spontaneously and without noise" (Foucault 1995, 206).

Here, it is essential to point out that:

One way that the information panopticon departs from Bentham's principles is that it is hierarchically organized. At every level of the organization, the observer is as likely to be a target of technical control as its vehicle. (Zuboff 1988, 337)

This is where a crucial difference between Marcus' Information Panopticon and the Information Panopticon set up by the Masked Freaks comes in. Marcus, despite being able to 
control the movements of those below him in the rung, to a certain extent, is "always doing just what the network wants" (Ezez. 2016). While Marcus might be at the topmost rung of the Information Panopticon he creates, he is answerable to Vicki for whatever decisions he takes. Hence, his Information Panopticon is enmeshed within a larger, hierarchal class structure. The Masked Freaks' Information Panopticon, on the other hand, is completely independent and unquestionable. This is clearly reflected when Marcus asks one of them:

Marcus: Who put you up to this anyway? Was it the network?

Masked Freak (scoffs): Why would we need them? We've got all the money we need. And, total creative control. (Ezez. 2016)

Hence, the hierarchy that exists within the Masked Freaks Information Panopticon is completely independent. This absolute hierarchical organization of their Information Panopticon is precisely what the Masked Freaks exploit in the prank that they play. The hierarchical organization of the larger Information Panopticon in Scare Campaign (the one created by the Masked Freaks) can be roughly traced based on the characters' visual access to space and their access to information. Emma is on the lowest rung owing to her absolute visibility and her complete lack of access to information or rather, her access to incorrect information. Trent, Suze, J.D. and Tony are on the rung above Emma because of their absolute visibility and because they have access to certain information that she does not but don't have access to the control room which is the means to surveillance. Marcus and Dick are on the rung above because they are only visible to the Masked Freaks and have their hands on the information Emma does not while also having access to the control room. Abby is on the rung above Marcus and Dick since she is what Marcus calls "the mole" (Ezez. 2016): an accomplice of the Masked Freaks posing as a member of the Scare Campaign crew, and hence has information that the rest of the Scare Campaign crew does not but, however, she is absolutely visible. Finally, the Masked Freaks are on the topmost 
rung of this Information Panopticon in the film through their absolute invisibility and complete access to information that anyone else in the Scare Campaign crew except Abby does not have. Marcus' lack of control over the situations around him despite all his access to power then, can be attributed largely to the presence of someone above him in the hierarchy, whose access to power is comparatively more unrestrained than his.

One can therefore say that the invisibility that the Masked Freaks' Information Panopticon in Scare Campaign thrives on puts them at the very top of the film's Information Panopticon's hierarchical structure.

\section{Visibility in the Masked Freaks' Information Panopticon}

In the context of an Information Panopticon, visibility shouldn't be taken merely in the literal sense. As Zuboff $(1988,322)$ points out, transparency achieved through illumination by the means of information also gives one access to power. Essentially, being kept track of even indirectly, without being observed visually, makes one vulnerable to having power exercised over him/ her. This idea can be best understood through the character of Abby and the role that she plays in Scare Campaign. When Vicki shows Marcus and the rest of the Scare Campaign crew a video of the Masked Freaks, one of the Masked Freaks in the video says "[w]e are watching, we are recording, expect us" (Ezez. 2016). Ironically, much to the horror of the audience, it is revealed at the very end of the film that the Masked Freaks had been "watching" the Scare Campaign crew even before this warning was dished out. Abby, whom Marcus interviews that morning as the newest addition to the Scare Campaign crew, actually turns out to be an accomplice of the Masked Freaks. Since Abby is planted by the Masked Freaks to gather information about the Scare Campaign crew and their next prank, one can say that she serves as their 'eyes' within the Scare 
Campaign camp. The vitality of this information Abby provides the Masked Freaks is indicated perfectly in the scene where Marcus and Emma find J.D. dead:

Marcus: Like I said, J.D. is not the mole.

Emma: What are you talking about?

Marcus: What do you think, this a crazy co-incidence Emy? They couldn't have done this without any inside information. (Ezez. 2016)

It follows that the Masked Freaks had access to information about the Scare Campaign's next prank, quite some time before the prank was actually about to be played. As an extension, it can be said that the Masked Freaks' Information Panopticon had been set up well before they started surveying the Scare Campaign crew visually through video cameras for the prank. It is hence, clear that the whole crew of Scare Campaign was being "watched" long before they were actually, literally, visible. Vicki tells the crew of Scare Campaign while talking to them about the Masked Freaks that "it's proving very hard to get a peek on them" (Ezez. 2016). This statement points out at the outset itself that not only are the Masked Freaks literally invisible unless they want to be seen, but the impossibility of contacting them or knowing anything at all about their identity, helps them maintain their invisibility to a much larger extent. This sense of the Masked Freaks invisibility is only heightened when Vicki tells the Scare Campaign crew: "It crept up on us while we were looking the other way!" (Ezez. 2016) Once Marcus and Emma find out that their original prank has been sabotaged by the Masked Freaks, they receive a phone call over which one of the Masked Freaks tells them “[w]e are watching, we are recording, you didn’t expect us" (Ezez. 2016).This statement takes a whole new dimension when seen in light of the earlier warning given out in the video Vicki shows the Scare Campaign crew. When one of the Masked Freaks repeats the warning at the end when he lets Emma leave with Abby, it foregrounds the fact that it could have been any random group of people that they chose to keep track of. One can possibly look at 
this instance as the foundation for a counter-argument to Goldenfein's claim that "contemporary types of visuality" differ from the visibility in Bentham's Panopticon. The point that the Masked Freaks bring out, can be metonymically extended to say that in the present age of digital surveillance, with all the various kinds of technological advancements that have come in, anyone can be subjected to constant surveillance anytime. Hence, it would be fair to say that the Information Panopticon created in Scare Campaign and, by extension, the several Information Panopticons present out there in the age of digital surveillance fit Bentham's requirement that "power should be visible and unverifiable" (Foucault 1995, 201). Again, visibility here shouldn't be taken in the literal sense. The mere awareness of the fact that several places are under video surveillance and anyone, anytime can be watching us, is enough to create 'visibility'.

It is, therefore, clearly seen that the Masked Freaks' Information Panopticon in the film is extremely thorough and not restricted solely to literal visibility. One can also conclude from these discussions that the Information Panopticon can be used to discipline and maintain power just like Bentham's Panopticon.

\section{The Spatiality of the Information Panopticon in Scare Campaign and its relation with visibility and power}

Thus far, this paper has looked at how both power and information (or the Foucauldian trope of Knowledge) function in the Information Panopticon in Scare Campaign. However, one must point out that:

The power-knowledge link is acknowledged by every Foucauldian scholar, but for Foucault himself the relationship was embedded in a trialectic of power, knowledge, and space. (Soja 1996, 148).

Given that for Foucault, spatiality plays such pivotal role when it comes to the exercising of power, it makes sense to take a look at the spatiality of the Information Panopticon in Scare 
Campaign and the possible allusions that can be read into it. The Information Panopticon in Scare Campaign is set up in a particularly interesting space. The prank location that the Scare Campaign crew chooses and where they eventually end up getting pranked by the Masked Freaks is an old building that used to be a dungeon. A Panopticon "reverses the principle of the dungeon; or rather of its three functions - to enclose, to deprive of light and to hide - it preserves only the first and eliminates the other two" (Foucault 1995, 200). In light of this statement, one can say that by setting up a Panopticon inside a (former) dungeon, what the pranksters effectually do is that they club two of the most intimidating ideas, when it comes to the exercise of power. This can be seen as an allusion to how technological advances have taken the possibilities of exercising power to a whole new level. What Koskela calls the "“spatialisation of power"” $(2003,296)$ is clearly marked out by the hierarchy of the Information Panopticon in Scare Campaign. Marcus' power is 'spatialised' by his access to the control room which is the 'space' for access to power through surveillance. His lack thereof and the Masked Freaks' access to power can be attributed to the fact that the physical spaces they occupy in the building are not accessible (visible) to anyone else, not even the audience. Even in the prank that the Scare Campaign crew attempts to pull off on Emma, what makes Trent so powerful and intimidating to Emma is that he "know[s] his way around. All the nooks and crannies. All the hiding spots. All the places you should never, ever go" (Ezez. 2016). Trent's pretense of a familiarity with the spatial arrangement of the building, the notion that he has been to and visually experienced every place, gives him the ability to exercise power over Emma in the prank.

Having discussed the way space has an effect on power, it is also essential to point out that "not only is space crucial to the exercise of power but, reciprocally, power also creates a particular kind of space" (Koskela 2000, 257). Looking at this dimension of the power-relations in the 
Information Panopticon in the film makes it clear that the characters often occupy spaces by virtue of their access to or lack of power. One can also say that, in exercising power, those on the higher rungs of the Information Panopticon in the film, control the spaces that those on the rung below them occupy, to a certain extent. This is exemplified in how the actors of the Scare Campaign crew are made to adapt their plans when Trent takes a different route and reaches the prank location sooner than expected. In instructing Emma and Suze to get into spaces which make them visible sooner than expected, Marcus and Dick expose them to the possibility of being observed. They do this because of the fact that they have access to power via their access to the visuals of the parking lot. And because of the very same fact, they remain free from the others' gazes under the pretext of observing the stooge's movements. Furthermore, the ones sitting in the control rooms or with the most amount of information in Scare Campaign's Information Panopticon have greater access to power by virtue of the fact that a larger amount of space is visually accessible to them: the larger the visual spectrum, the greater the access to power. This shows how the spatiality and the access to power that it brings to the characters is pivotally linked with the hierarchy of the Information Panopticon in the film. The Masked Freaks perched at the top of the hierarchy have visual access to the largest amount of space and, hence have the greatest access to power. Emma, on the other hand, only has literal visual access to the space she is present in and even her vision of other spaces through information is blurred because she is the one being pranked. Essentially, the Masked Freaks' access to power comes from the visually and literally inaccessible space that they occupy as well as the access they have to every bit of space within the building. Emma's lack on the other hand, can be attributed to her lack of visual access to any other space except the one she is in and to the fact that the spaces that she occupies are visually accessible very easily. A similar kind of relation between space and its visibility and the access to power can be traced for every other character in the film. 
While space and the visual access to it help the Masked Freaks to exercise power, one must also point out that their information Panopticon, like any other, is "freed from the constraints of space and time" (Zuboff 1988, 332). By virtue of this, the Information Panopticon that the Masked Freaks create allows them to access spaces visually without being bound by time or the physical space they occupy. This unboundedness only further facilitates the exercise of their power over the stooges. This is best seen in how the Masked Freaks show Marcus, just before burning him alive, that the visuals he and Emma saw of Abby getting suffocated in an air-tight coffin, had been practised and shot well before-hand. Despite the fact that space is such a crucial element when it comes to the exercise of power in Foucauldian studies, one must also point out that it is not an absolute necessity:

[T]here is nothing about enclosure per se that requires its conception in terms of a material structure, indeed, at times for Foucault enclosure is more a property of the psyche than a concrete spatial arrangement. (Simon 2005, 9).

Hence, Emma's 'enclosure' into Marcus' Information Panopticon as well as the whole Scare Campaign crew's 'enclosure' into the Masked Freaks' Information Panopticon, while being heavily interlinked with material spatial arrangement, are not completely reliant on it. The enclosure of the stooges within Information Panopticons without being restricted to space is clear in how the Masked Freaks set up an Information Panopticon by planting Abby as a mole way before anyone has so much as set a foot on the prank location.

It is hence clear that space and the visual access to it gives one access to power in the Information Panopticon in Scare Campaign as well as the spaces and the access to them being determined by one's access to power. However, it must also be kept in mind that despite being a crucial cog in the wheel of power, a specific material spatial arrangement is not absolutely 
necessary to have access to power, as seen through the film. Space and the visual access to it can therefore, be understood as sharing a reciprocal relationship with access to power in the Information Panopticon in Scare Campaign.

\section{Conclusion}

Cameron and Colin Cairnes' Scare Campaign, hence, makes for an interesting study of the various aspects of an Information Panopticon. The Information Panopticon created in the film, while displaying a hierarchical structure, also goes beyond the bounds of literal visibility. Above all, it is by means of this Information Panopticon that the pranksters in the film exercise their power over the stooges and prank them successfully. In doing this, the role of the spatial domains they take up is crucial as well.

\section{BIBLIOGRAPHY}

Foucault, Michel. 1995. "Panopticism.” In Discipline and Punish: The Birth of the Prison. $1^{\text {st }}$ arg. New York: Vintage Books.

Koskela, Hille. 2000. "'The gaze without eyes': video-surveillance and the changing nature of urban space". Progress in Human Geography 24 (2): 243-265.

http://old.geog.psu.edu/courses/geog497b/Readings/Koskela.pdf .

Koskela, Hille. 2003. "Cam Era' - the contemporary urban Panopticon". Surveillance \& Society 1 (3): 292-313. http://ojs.library.queensu.ca/index.php/surveillance-and-

society/article/view/3342.

McMullan, Thomas. 2015. "What does the panopticon mean in the age of digital surveillance?". The Guardian. https://www.theguardian.com/technology/2015/jul/23/panopticon-digitalsurveillance-jeremy-bentham.

Ezez. 2016. Scare Campaign. Video. Australia: Cameron Cairnes and Colin Cairnes, Bonsai Films. 
Simon, Bart. 2005. "The Return of Panopticism: Supervision, Subjection and the New Surveillance". Surveillance and Society 3 (1): 1-20.

http://ojs.library.queensu.ca/index.php/surveillance-and-society/article/view/3317.

Soja, Edward W. 1996. Thirdspace: Journeys to Los Angeles and other Real-and-Imagine Places. 1st arg. Cambridge, Mass.: Blackwell.

Zuboff, Shoshana. 1988. "The Information Panopticon." In In the Age of the Smart Machine: The Future of Work and Power. 1st arg. New York: Basic Books. 